\title{
ANALISIS MANAJEMEN KEPEMIMPINAN MELALUI APLIKASI SWOT PADA ORGANISASI PSSI (PERSATUAN SEPAKBOLA SELURUH INDONESIA)
}

\author{
Andri Veno \\ Pusat Studi Penelitian Pengembangan Manajemen dan Bisnis \\ (Fakultas Ekonomi dan Bisnis Universitas Muhammadiyah Surakarta) \\ Jl. A. Yani Pabelan Kartasura Surakarta \\ Email : veno.focus@gmail.com
}

\begin{abstract}
Abstraksi: PSSI Sebagai organisasi yang menaungi sepakbola di Indonesia melakukan perubahan dalam organisasinya adalah mempunyai beberapa tujuan organisasi yang ingin dicapai yang berfungsi untuk tetap berjalan sesuai dengan aturan FIFA dan tetap sesuai jalurnya hukum di negara Indonesia demi kemakmuran pelaku sepakbola sehingga dapat berprestasi. Dalam membenahi PSSI pemerintah dalam hal ini dibawah kemenporan berupaya mengambil alih peran PSSI sementara untuk membenahi organisasi didalam kepengurusannya, sehingga Isu yang muncul mengenai mafia dan kepentingan politik di dalam organisasi PSSI segera terselesaikan. Manajemen perubahan yang dilakukan pemerintah diharapakan menjadi tolak balik pembangunan organisasi PSSI dimasa yang akan datang sehingga sejalan dengan misi dan visi PSSI. Langkah yang dilakukan pemerintah saat ini dibawah kemenporan yang dilakukan saat ini agar para pelaku sepakbola tetap bisa menjalankan pekerjaannya dengan melakukan turnamen dengan sistem kompetisi. Turnamen yang digelar akan tetap mengerakkan roda perekonomian dan kesejahteraan para pelaku sepakbola maupun pengusaha ditanah air.
\end{abstract}

Kata Kunci : Persatuan Sepakbola Seluruh Indonesia (PSSI), Politik, Manajemen perubahan, SWOT

\begin{abstract}
Just like an umbrella, PSSI, official Indonesian football organization have been changing to fulfill several organizational goals, and still undergoing some functions alongside regulation of FIFA and Indonesian law for the glorious and prestigious Indonesian football. In reorganizing PSSI, the government under The Ministry of Educations and Sports (Kemenpora) takes over PSSI's role temporarily to rearrange management of the organization, and then the problems regarding to mafia and political issues inside of PSSI management can be resolved immediately. The management changes by the government is expected to become a turning point for the development of the future PSSI organization, so it can be reciprocal both with mission and vision of PSSI. The recent step from the government under Kemenpora in order to make all of the football perpetrators running their job is hold a tournament with competition system.
\end{abstract}

Keyword : Football Association of Indonesia (PSSI), Politics, Changing management, SWOT

\section{LATAR BELAKANG}

Sepakbola merupakan salah satu olah raga yang menjadi favorit di muka bumi ini, Dinegara sepakbola seperti inggris (karena di inggris assosiasi sepakbolanya FA merupakan yang tertua didunia dan FA lah yang pertamakali membuat peraturan sepakbola) sepakbola secara ekstrem diibaratkan sudah seperti agama mereka yang dianut dan klub sepakbola maupun timnas sepakbola bagaikan madzab/alirannya oleh para pecinta/ pendukung dari suatu klub di masing - masing kota dan menjadi topik pembicaraan yang hangat di setiap 'kedai kopi' mereka tiap kali menjelang atau setelah pertandingan antar klub/ negara mereka dimainkan. Sepak bola adalah olah raga yang bisa dibilang sangat simpel.

Tidak terkecuali dinegara Indonesia sepak bola sudah menjadi tontonan yang sangat menghibur bagi masyarakat Indonesia. Bisa dilihat disetiap daerah mempunyai team kebanggaan dengan komunitas supporter yang 
fanatic. Sepakbola sudah menjadi sebuah Industri bagi pergerakan ekonomi. Mulai dari pemain, pelatih, penjual merchandiser, penjual makanan dan minuman, penginapan dan masih banyak lagi. Tetapi di erah tahun 2011 PSSI yang menaungi kompetisi sepakbola di Indonesia, di bawah Ketua Umum Djohar Arifin Husin, telah mencabut delegasi penyelenggaraan kompetisi profesional dari PT LI melalui Surat Keputusan Nomor SKEP/21/JAH/VIII/2011 dan menunjuk PT LPIS sebagai penyelenggara kompetisi profesional yang baru, IPL. Penentangan terhadap keputusan PSSI mengenai jumlah peserta IPL oleh sebagian klub eks peserta LSI membuat klub-klub tersebut meminta PT LI kembali menyelenggarakan LSI sesuai dengan amanat Kongres II PSSI di Bali. Klub-klub tersebut berpandangan bahwa penunjukan PT LI adalah melalui kongres sehingga tidak dapat dicabut begitu saja hanya melalui surat keputusan yang ditandatangani oleh ketua umum. PT LI kemudian berencana menyelenggarakan RUPS untuk mengalihkan 99\% saham dari PSSI kepada klub-klub serta memilih pengurus perusahaan yang baru. PSSI menentang penyelenggaraan RUPS itu sejak dari perencanaannya dengan alasan surat pemberitahuan yang salah alamat dan dikirimkan terlalu dekat dengan waktu penyelenggaraan. Selain itu PSSI sendiri telah mencabut mandat penyelenggaraan kompetisi dari PT LI. RUPS dihadiri oleh 13 klub, di mana 1 klub yaitu Persib tidak mengisi daftar hadir. RUPS juga dihadiri oleh beberapa perwakilan pengurus provinsi PSSI dan empat anggota Komite Eksekutif PSSI, yakni La Nyalla Machmud Mattalatti, Toni Apriliani, Robertho Rouw, dan Erwin Dwi Budiman. Dalam RUPS tersebut, disepakati untuk menyelenggarakan LSI 2011-2012 dengan kick-off pada tanggal 1 Desember 2011.

Kisruh yang terjadi saat itu sebenarnya rangkaian kisruh sejak dualismekepemimpinan PSSI waktu lalu. Pemerintah, dalam hal ini Kementrian Pemuda dan Olahraga ingin kisruh dua organisasi yang terjadi pada Arema dan Persebaya diselesaikan sesuai mekanisme yang ada, bagaimana penyelesaian melalui badan yang dibentuk oleh pemerintah, yakni Badan Olahraga Profesional Indonesia (BOPI). Namun Persatuan Sepakbola Seluruh
Indonesia (PSSI) seolah mengabaikan anjuran pemerintah hanya karena PSSI punya otoritas di bawah naungan AFC dan FIFA. Menteri Pemuda dan Olah Raga (Menpora), Imam Nahrowi yang mengklaim ingin membenahi organisasi PSSI sesuai hukum Indonesia, beberapa kali telah memperingatkan PSSI untuk mentaati rekomendasi BOPI. Tapi PSSI tetap tidak memperhatikannya. Imam akhirnya mengeluarkan surat yang menyatakan pembekuan PSSI. Dalam suratnya itu, Menpora memberikan sanksi administratif terhadap PSSI, yaitu setiap kegiatannya tak diakui oleh pemerintah, begitu pun dengan hasil Kongres Luar Biasa (KLB) PSSI di Surabaya yang telah menentapkan La Nyalla Mahmud Mattalitti sebagai Ketua Umum PSSI.

Dalam makalah ini disajikan manajemen perubahan dalam implementasi organisasi kearah yang lebih baik sesuai dengan aturan organisasi sepakbola dunia FIFA dan kesejahteraan bagi para pelaku sepakbola di Indonesia.

\section{TUJUAN PERUBAHAN}

PSSI Sebagai organisasi yang menaungi sepakbola di Indonesia melakukan perubahan dalam organisasinya adalah mempunyai beberapa tujuan organisasi yang ingin dicapai yang berfungsi untuk tetap berjalan sesuai dengan aturan FIFA dan tetap sesuai jalurnya hukum di negara Indonesia demi kemakmuran pelaku sepakbola sehingga dapat berprestasi. Beberapa tujuan perubahan ini adalah sebagai berikut :

1. Perubahan dalam upaya membangun dan mengembangkan organisasi PSSI dalam mewujudkan prestasi yang lebih baik di internasional.

2. Perubahan dalam upaya memberikan sumbangan bagi perekonomian negara pada umumnya, dan meningkatkan kesejahteraan pelaku sepakbola serta komponen usaha yang bersangkutan di tanah air demi pembangunan nasional.

\section{MANFAAT PERUBAHAN}

Manfaat manajemen perubahan secara umum adalah dapat dirasakan apabila 
semua lini pelaku industry sepakbola saling mendukung perubahan tersebut. Sedang pada PSSI sendiri, khususnya akan bermanfaat bagi tingkat kepercayaan masyarakat dalam memajukan persepakbolaan tanah air.

\section{LANDASAN TEORITIS}

Perlu dipahami bahwa tidak semua perubahan yang terjadi akan berdampak kondisi yang lebih baik, hingga dalam hal demikian tentu perlu diupayakan agar bila dimungkinkan perubahan diarahkan kearah hal yang lebih baik dibandingkan dengan kondisi sebelumnya. Transisi dari kondisi awal hingga kondisi kemudian memerlukan suatu proses tranformasi, yang tidak selalu berlangsung dengan lancarnya, mengingat bahwa perubahan-perubahan sering kali aneka macam konflik yang muncul. Salah satu sasaran manajemen perubahan "mengupayakan agar proses tranformasi tersebut berlangsung dalam waktu yang relative cepat dengan kesulitankesulitan seminimal mungkin" pembahasan perubahan dan proses perubahan, biasanya dilakukan orang melalui focus perubahan keorganisasian (organization change.

\section{PENTINGNYA MANAJEMEN PERUBAHAN}

Perubahan merupakan suatu fenomena yang pernah terjadi dalam kehidupan organisasi, meskipun banyak yang berpendapat bahwa kecepatan dan besaran perubahan telah meningkat secara signifikan beberapa tahun belakangan ini. Oleh karena itu, kita melihat bahwa dalam waktu yang relatif pendek, kebanyakan orgaisasi dan pekerjanya telah menglamai perubahan secara subtansial tentang apa yang mereka lakukan dan bagaimana mereka melakukannya (Burnes, 200:250).

\section{PENDEKATAN MANAJEMEN PERUBAHAN}

1. Planned Change (Perubahan Terencana) Bullock dan Batten (Burnes, 200:272) mengemukakan bahwa untuk melakukan perubahan terencana perlu dilakukan empat fase tindakan yaitu sebagai berikut: a. Exploration phase (fase eksplorasi).

b. Planning phase (fase perencanaan).

c. Action phase (fase tindakan).

d. Integration phase (fase integrasi).

2. Emergent Approach (Pendekatan Darurat) Emergent approach memberikan arahan dengan melakukan penekanan pada lima gambaran organisasi yang dapat mengembangkan atau menghalangi keberhasilan perubahan yaitu sebagai berikut:

a. Organizational structure (struktur organisasi).

b. Organizational culture (budaya organisasi).

c. Organizational learning (organisasi pembelajaran).

d. Manajerial behaviour (perilaku manajerial).

e. Power and politics (kekuatan dan politik).

Dalam melakukan emergent change, Pettigrew dan Whipp (Burnes, 2000:294) mengusulkan model untuk mengelola perubahan strategis dan operasional dengan melibatkan lima faktor yang saling berkaitan yaitu sebagai berikut:

1. Environmental assesment (penelusuran lingkungan).

2. Leading change (memimpin perubahan).

3. Linking strategic and operational change (menghubungkan perubahan strategis dan operasional).

4. Human resources sebagai assets dan liabilities (sumber daya manusia sebagai kekuatan dan beban).

\section{MODEL MANAJEMEN PERUBAHAN}

1. Jones, ((2002), :645-646) dalam Winardi 2004 mengemukakan bahwa perubahan organisasional dapat aneka macam kekuatan yang membantu dan yang menghalangi perubahan organisasi :

Kekuatan yang membantu :
a. Kekuatan-kekuatan kompetitif
b. Kekuatan ekonomi dan politik
c. Kekuatan-kekuatan global
d. Kekuatan-kekuatan demografik dan kekuatan social
e. Kekuatan-kekuatan etika 
Kekuatan yang menghalangi :
a. Kendala-kendala keorganisasian kekuasaan dan konflik
b. Perbedaan-perbedaan dalam orientasi fungsional struktur mekanistik
c. Kendala-kendala kelompok, norma- norma kelompok, kohesitivitas kelompok

d. Pemikiran kelompok dan ekskalasi komitmen, kendala-kendalaindividu, ketidakpastian dan perasaan tidak aman, persepsi selektif dan retensi kebiasaan

2. Target-target keorganisasian yang dapat diubah dan metode-metode untuk menghadapinya :

Tabel 1.

\begin{tabular}{|c|c|}
\hline Target & Metode-metode perubahan-perubahan yang dapat diterapkan \\
\hline $\begin{array}{l}\text { Tujuan-tujuan dan } \\
\text { sasaran-sasaran }\end{array}$ & $\begin{array}{l}\text { Jelaskan misi secara keseluruhan; laksanakan modifikasi sasaran- } \\
\text { sasaran yang ada; terapkan asas manajemen berdasarkan sasaran-saran }\end{array}$ \\
\hline Kultur & $\begin{array}{l}\text { Laksanakan klarifikasi, modifikasi, dan atau menciptakan kenyakinan- } \\
\text { kenyakinan inti dan nilai-nilai guna membantu membentuk perilaku } \\
\text { individu-individu dan kelompok-kelompok }\end{array}$ \\
\hline Strategi & $\begin{array}{l}\text { Modifikasi rencan-rencana strategik; modifikasi rencana-rencana } \\
\text { operasional; modifikasi kebijakan-kebijakan serta prosedur-prosedur }\end{array}$ \\
\hline Tugas-tugas & $\begin{array}{l}\text { Modifikasi desain pekerjaan; terapkan perkayaan pekerjaan (job } \\
\text { enrichment) dan kelompok-kelompok kerja otonomi }\end{array}$ \\
\hline Teknologi & $\begin{array}{l}\text { Perbaikan peralatan serta fasilitas-fasilitas; perbaikan metode-metode } \\
\text { dan arus pekerjaan }\end{array}$ \\
\hline Orang-orang & $\begin{array}{l}\text { Modifikasi kriteria seleksi; modifikasi praktik-pratik recruiting } \\
\text { terapkan program-program pelatihan dan pengembangan klarifikasi } \\
\text { peranan dan ekspetasi-ekspetasi }\end{array}$ \\
\hline Struktur & $\begin{array}{l}\text { Modifikasi uraian pekerjaan; modifikasi desain keorganisasian } \\
\text { sesuaikan mekanisme-mekanisme koordinasi, modifikasi penyebaran } \\
\text { otoritas }\end{array}$ \\
\hline
\end{tabular}

\section{ANALISIS SWOT}

Analisis SWOT secara sederhana dipahami sebagai pengujian terhadap kekuatan dan kelemahan internal sebuah organisasi, serta kesempatan dan ancaman lingkungan eksternalnya. SWOT adalah perangkat umum yang didesain dan digunakan sebagai langkah awal dalam proses pembuatan keputusan dan sebagai perencanaan strategis dalam berbagai terapan (Johnson, dkk., 1989; Bartol dkk., 1991). Jika hal ini digunakan dengan benar, maka dimungkinkan bagi sebuah sekolah kejuruan untuk mendapatkan sebuah gambaran menyeluruh mengenai situasi sekolah itu dalam hubungannya dengan masyarakat, lembaga-lembaga pendidikan yang lain, dan lapangan industri yang akan dimasuki oleh murid-muridnya. Sedangkan pemahaman mengenai faktor-faktor eksternal, (terdiri atas ancaman dan kesempatan), yang digabungkan dengan suatu pengujian mengenai kekuatan dan kelemahan akan membantu dalam mengembangkan sebuah visi tentang masa depan. Prakiraan seperti ini diterapkan dengan mulai membuat program yang kompeten atau mengganti programprogram yang tidak relevan serta berlebihan dengan program yang lebih inovatif dan relevan.

Langkah pertama dalam analisis SWOT adalah membuat sebuah lembaran kerja dengan jalan menarik sebuah garis persilangan yang membentuk empat kuadran, keadaan masing-masing satu untuk kekuatan, kelemahan, peluang/kesempatan, dan ancaman. Secara garis besar lembaran kerja tersebut diperlihatkan dalam lembar-1. 
Langkah berikutnya adalah membuat daftar item spesifik yang berhubungan dengan masalah yang dihadapi di bawah topik masing. Dengan membatasi daftar sampai 10 poin atau lebih sedikit, untuk menghindari generalisasi yang berlebihan (Johnson, et al., 1989).

SWOT dapat dilaksanakan oleh para karyawan secara individual atau secara kelompok dalam organisasi. Teknik secara kelompok akan lebih efektif khususnya dalam pengadaan struktur, objektifitas, kejelasan dan fokus untuk diskusi mengenai strategi, sehingga tidak akan cenderung melantur, dan bahkan akan terkena pengaruh politik atau kesenangan (interest) perseorangan yang kuat (Glass, 1991). Hal yang harus disadari jika bekerja secara kelompok dalam bidang keuangan, maka akan muncul tiga sikap yang terangan-terangan dari para karyawan di mana tergantung masa kerja mereka masing-masing. Karyawan yang mempunyai pengalaman dan masa kerja lebih lama lebih cenderung menjadi yang paling partisipatif dan receptive akan ide-ide baru.

SWOT harus mencakup semua aspek/ area berikut ini, yang masing-masing dapat merupakan sumber kekuatan, kelemahan, kesempatan, atau ancaman.

\section{PEMBAHASAN}

Persatuan Sepakbola Seluruh Indonesia didirikan pada tanggal 19 April 1930 oleh Insinyur Soeratin yang menjadi ketua umum PSSI pertama, bersama-sama dengan kawan-kawannya dari tujuh voetbal bond. Tujuh anggota voetbal bond itu adalah VIJ (Jakarta, sekarang Persija Jakarta) diwakilkan oleh Soekardi, BIVB (Bandung, sekarang Persib Maung Bandung) diwakilkan oleh Mr. Syamsoedin, MIVB (sekarang PPSM Magelang) diwakilkan oleh E. Mangindaan, MVB (Madiun) diwakilkan oleh M. Dharsono, SIVB (sekarang Persebaya Surabaya) diwakilkan oleh R. Pamoedji, VVB (Surakarta, sekarang Persis Solo) diwakilkan oleh Saronto, Soedaryo Tjokrosisworo dan Soetarman, and PSIM (Yogyakarta) diwakilkan oleh HA Hamid, Daslam, dan Amir Noto.

PSSI didirikan 15 tahun sebelum Indonesia merdeka, dimasa penjajahan Hindia Belanda hingga berdirinya Republik Indonesia. PSSI disamping dikenal sebagai organisasi sepakbola nasional juga dikenal sebagai alat perjuangan bangsa untuk mencapai dan mengisi kemerdekaan. Oleh karena itu, PSSI memiliki kekhasan tersendiri dibandingkan anggota FIFA lainnya karena ia lahir sebelum negaranya berdiri, atau lebih tepatnya PSSI lahir ditengah perjuangan bangsa untuk merebut kemerdekaan. PSSI pada saat berdiri berperan ganda, yaitu mengelola sepakbola nasional dan memupuk semangat kebangsaan serta menjalin persatuan dan kesatuan bangsa.

Di masa penjajahan peranan PSSI memupuksemangatkebangsaanlebihmenonjol dibandingkan dengan prestasi sepakbolanya sendiri. Hal ini disebabkan karena negaranya belum berdiri sehingga belum dapat menjadi anggota FIFA. Karena belum terdaftar menjadi anggota Federasi Sepakbola Dunia itu, PSSI tidak dapat mengikuti kejuaraan resmi sepakbola internasional. PSSI hanya dapat melakukan pertandingan persahanbatan dengan kesebelasan negara tetangga seperti melawan Nan Hwa dari China pada tahun 1937. PSSI juga pernah merasakan ikut turnamen terbesar di dunia yaitu Kejuaraan Dunia di Perancis pada tahun 1938, namun dengan nama kesebelasan Hindia Belanda.

Pada tahun 1950, PSSI mengadakan kongres dan kompetisi kejuaraan nasional pertama setelah merdeka di kota Semarang. Hasil dari kongres ini, kepengurusan menyusun program delapan tahun dari tahun 1950 sampai dengan tahun 1958, dibagi dua tahap, dan klompetisi dengan jelas disebutkan sebagai landasan utama pembinaan prestasi menuju tercapainya target pada tahun terakhir yaitu tiga besar Asia. Persib pada saat itu menjadi juara kompetisi kejuaraan nasional yang pertama kali digelar setelah Indonesia merdeka.

Debut pertama PSSI di arena internasional ialah mengikuti sepakbola Asia Games I tahun 1951 di New Delhi, India. Dalam even tersebut PSSI harus tersisih dalam babak penyisihan. Baru pada Asia Games II tahun 1954, PSSI dapat mengukir prestasi sebagai semifinalis. Pada tahun 1952 PSSI resmi diterima menjadi anggota FIFA.

Pada masa lalu prestasi PSSI cukup bagus diantaranya lolos dalam sepakbola olimpiade di Melbourne Australia pada tahun 1956, Juara Merdeka Games di Kuala Lumpur Malaya ( sekarang Malaysia ) yang menjadi ajang 
turnamen sepakbola internasional bergengsi di Asia pada waktu itu, tidak kalah dengan para seniornya pemain-pemain muda PSSI menggondol gelar juara Kejuaraan Sepakbola Junior pada tahun 1962.

Namun pada Asian Games IV tahun 1962 di Jakarta terjadi skandal yang berbuntut banyaknya pemain inti PSSI yang terkena skorsing sehingga membuat prestasi PSSI menurun. PSSI baru kembali disegani pada tahun tujuhpuluhan, dengan menyabet banyak gelar di berbagai turnamen sepakbola Asia seperti President Cup Seoul, Kings Cup Bangkok, Pesta Sukan Singapura, dan Aniversary Cup Jakarta. Pada tahun delapan puluhan, PSSI juga dapat kembali menjadi semifinalis Asian Games di Seoul tahun 1986, dan menjadi juara di Sea Games tahun 1987 di Jakarta. Namun pada saat ini prestasi-prestasi dahulu sudah tidak terlihat lagi. PSSI dahulu yang disegani di wilayah Asia, sekarang sudah tidak bertaring lagi karena prestasi yang surut. PSSI jarang mendapatkan gelar baik di kawasan Asia Tenggara maupun Asia pada keseluruhannya.

\section{MISI DAN VISI PSSI}

1. Visi:
a. Sepakbola sebagai tujuan hidup
b. Kompetisi sebagai jantungnya prestasi
c. Prestasi sebagai tujuan utama
d. Sepakbola sebagai industri olahraga
e. Mempersatukan piring pecah PSSI

2. Misi:

a. Mencari pemain muda yang bertalenta, pintar, berdaya tahan tinngi, didukung oleh orang tua dan keluarga serta mempunyai komitmen bahwa sepakbola adalah tujuan hidupnya sama dengan profesi lainnya. b. Kompetisi yang merupakan jantungnya prestasi, perlu pembenahan disegala aspek, dimulai dengan sarana lapangan yang berkwalitas, wasit yang berintegritas, pengurangan pemain asing serta mencari solusi dana atau sponsorship sebagai pengganti dana yang bersumber dari apbd.

c. Sebagai pengurus besar cabang olahraga, prestasi merupakan ukuran keberhasilan, oleh karena itu, kepengurusan pssi kedepan dari mulai yang paling bawah sampai dengan ketua umumnya harus dapat membuat program yangbertolok ukur kepada peningkatan prestasi dilapangan. ( program realistis dan optimis ).

d. Sebagai sebuah industri, klub dan kompetisi, pemain dan suporter yang merupakan asset terbesar club adalah bagian dari penggerak ekonomi di daerah yang dapat menyediakan lapangan pekerjaan dan usaha, oleh karena itu pengelolaan club, suporter dan pemyelengaraan kompetisi harus terus ditingkatkan kwalitasnya.

Perpecahan diantara anggota pssi, yang sudah sampai ke pengurus cabang, merupakan kesalahan sejarah sepakbola indonesia yang dibuat oleh kepengurusan pssi saat ini, kongres luar biasa, merupakan solusi untuk dapat mempersatukan kembali seluruh stake holder sepakboala nasional dan kongres luar biasa tersebut harus dapat dukungan baik secara langsung maupun tidak langsung, sekarang atau dikemudian hari oleh afc dan fifa. (http://www.kompasiana.com/guns.jax/ visi-dan-misi-untuk-persepakbolaan-indonesi a_551b5501a33311b023b65ddd 
Tabel 2. Analisa SWOT dari organisasi PSSI

Kekuatan
1. $\begin{aligned} & \text { Indonesia memiliki jumlah pemain } \\ & \text { sepakbola yang banyak (SDM yang } \\ & \text { Melimpah). }\end{aligned}$ $\begin{aligned} & \text { Sistem Kompetisi yang tidak } \\ & \text { jelas }\end{aligned}$

3. Masyarakat Indonesia menyukai sepakbola.

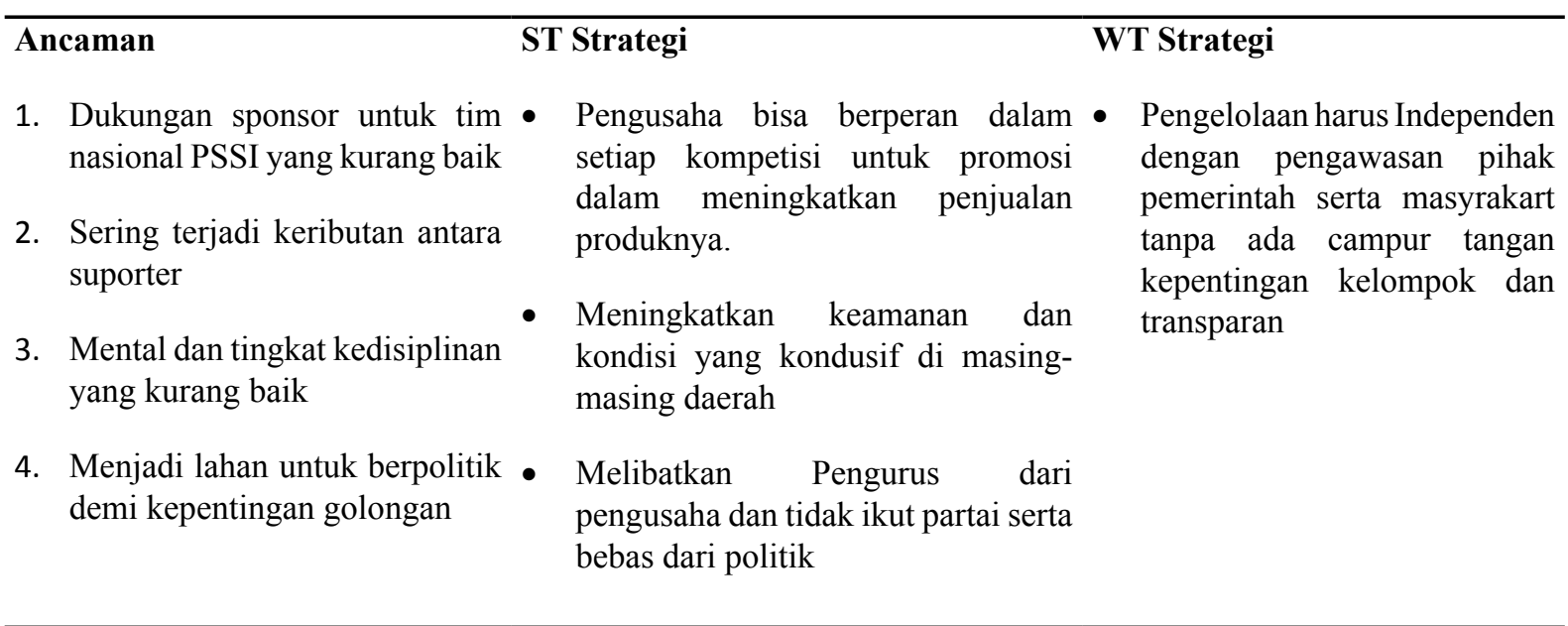

Berdasarkan analisis SWOT PSSI, masih banyak hal masih menjadi pembenahan di dalam organisasi PSSI, sebagaimana kita sadari, bahwa sepakbola, sejatinya adalah wahana belajar tentang kehidupan (school of life) akan nilai-nilai disiplin, fairplay dan respect. Sepakbola pun telah menjadi Peluang bisnis, menjadi salah satu elemen (penggerak) ekonomi global. Sepakbola memberi perubahan positif, kesetaraan hingga kesejahteraan. PSSI selalu ingin menjadi bagian, sekaligus menjadi pelaku dari kesukseksan sepakbola didunia.

Jalan menuju kesuksesan seperti yang diimpikan, penuh dengan tantangan dan kesulitan. Diperlukan perencanaan yang cermat, analisis yang dalam, target-target yang realistis dan terukur. Itulah sebabnya PSSI Strategic Plan dibuat, sebagai panduan bagi seluruh elemen organisasi. Tahun 2015, 
PSSI akan tetap fokus dan melanjutkan upaya peningkatan kualitas "the game" (sebuah pertandingan), sebagai upaya inti program. "The game" harus diterjemahkan dan difahami oleh semua pihak. Dengan basis strategic plan 2014, maka tahun 2015, PSSI sudah fokus, dalam 5 hal utama:

1. Football Development;

2. Reformasi Asprov (dan Liga Amatir);

3. Liga Profesional;

4. Tim Nasional; dan

5. (Governance \& Management).

Dengan adanya perubahan yang dilakukan diharapkan Klub dan pelaku sepakbola serta kompetisi yang berkualitas ditanah air maka akan menjadikan sebuah industry sepakbola yang lebih sejahtera dan akhirnya mendapatkan prestasi yang diharapkan masyarakat Indonesia.

\section{KESIMPULAN DAN SARAN}

\section{Kesimpulan}

1. Dalam membenahi PSSI pemerintah dalam hal ini dibawah kemenporan berupaya mengambil alih peran PSSI sementara untuk membenahi organisasi didalam kepengurusannya, sehingga Isu yang muncul mengenai mafia dan kepentingan politik di dalam organisasi PSSI segera terselesaikan. Manajemen perubahan yang dilakukan pemerintah diharapakan menjadi tolak balik pembangunan organisasi PSSI dimasa yang akan datang sehingga sejalan dengan misi dan visi PSSI. Meskipun harus menerima kenyataan dengan sangsi yang dijatuhkan FIFA sebagai induk organisasi sepakbola dunia. Sehingga berdampak pada semakin terpuruknya rangking sepakbola Indonesia di dunia.

2. Langkah yang dilakukan pemerintah saat ini dibawah kemenporan yang dilakukan saat ini agar para pelaku sepakbola tetap bisa menjalankan pekerjaannya dengan melakukan turnamen dengan sistem kompetisi. Turnamen yang digelar akan tetap mengerakkan roda perekonomian dan kesejahteraan para pelaku sepakbola maupun pengusaha ditanah air.

\section{Saran}

Permasalahan yang dihadapi persepakbolaan tanah air menjadi sangat rumit dikarenakan banyaknya kepentingan yang berkonflik. Dilema terjadi dalam tubuh pemerintahan dikarenakan beberapa peraturan statute FIFA tentang pelanggaran pihak ketiga untuk ikut campur dalam menyelesaikan konflik PSSI. Penerapan statuta FIFA mungkin mudah dilaksanakan oleh negara-negara maju di Eropa, akan tetapi berbeda kondisinya di negara dunia ketiga seperti Indonesia yang negara sedang mengatasi permasalahan dan regulasi kompetisi sepakbola. Di Eropa klub sepakbola berkembang secara professional, menggunakan dana klub dalam menjalankan klubnya, berbeda kondisinya dengan negara Indonesia klub masih mengandalkan dana APBD, APBN dan PSSI dalam menjalankannya. Hal itu menandakan bahwa sistem sepakbola di Indonesia masih belum mapan dan perlunya pengawasan dari pemerintah dalam menjalankan.

\section{DAFTAR PUSTAKA}

Winardi, 2005., "Manajemen Perubahan". Cetakan ke-1 Mei 2005, Prenada Media, Jakarta

Burnes, 2000., "The Culture of education". Cambrige MA : Harvard University Press.

Rungkuti, 1997., "Analisis SWOT teknik membedah kasus bisnis).Terbitan Pertama, PT Gramedia Pustaka Utama Agustus 1997.

Ulhao AD, 2013.,"Olah raga dan Politik Studi kasus peran pemerintah dalam konflik persatuan sepakbola seluruh Indonesia (PSSI)",Skripsi, Universitas Islam Negri Syarif Hidayatullah Jakarta"

https://id.wikipedia.org/wiki/Persatuan Sepak_Bola_Seluruh_Indonesia

https://id.wikipedia.org/wiki/Liga_Indonesia_ (perusahaan)

http://indonesianreview.com/ds-muftie/ kisruh-pssi-antara-intervensi-danprestasi 
http://www.kompasiana.com/guns.jax/visidan-misi-untuk-persepakbolaan-indone sia_551b5501a33311b023b65ddd 